\title{
Examining Professional Identity Formation Through the Ancient Art of Mask-Making
}

\author{
Mark B. Stephens, MD MS ${ }^{7}$, Karlen S. Bader, BS ${ }^{2}$, Kimberly R. Myers, PhD MA', \\ Melissa S. Walker, MA ATR ${ }^{3}$, and Lara Varpio, PhD ${ }^{2}$
}

'Penn State University College of Medicine, University Park, Hershey, PA, USA; ${ }^{2}$ Uniformed Services University of the Health Sciences, Bethesda, MD, USA; ${ }^{3}$ National Intrepid Center of Excellence, Bethesda, MD, USA

$\mathrm{J}$ Gen Intern Med 34(7):1113-5

DOI: $10.1007 / \mathrm{s} 11606-019-04954-3$

(๑) Society of General Internal Medicine 2019

\section{INTRODUCTION}

Professional identity formation (PIF) is a complex sociocultural process whereby medical students learn to think, feel, and act like physicians. This process is often unscripted and influenced by informal curricular elements. Medical schools must provide students with the scientific knowledge and clinical skills to practice medicine, and also with opportunities to develop a healthy professional identity - empowering them to "think, act and feel like a physician". ${ }^{\text {(p.1447) }}$ Developing a comfortable professional identity is a challenging process that requires self-awareness, and a habit of reflective practice. ${ }^{2}$ Alarmingly, rates of depression, burnout and suicide have increased sharply in medical students. ${ }^{2,}{ }^{3}$ Hypothesizing that a struggle in the process of identity formation is associated, we incorporate visual strategies to (re)introduce mask-making as a mechanism to foster PIF in the context of medical education.

\section{SETTING AND PARTICIPANTS}

Building on traditions of symbols and ceremony in times of transition, mask-making is markedly different from narrative strategies that are traditionally used to explore PIF in medical education. Masks have been used for centuries as a ritual to alter or explore new identities. Masks explore sociocultural perspectives of transition, environment, and learning to visually convey stories and stimulate emotions. ${ }^{4}$ While our focus has been on undergraduate medical education, we have also used mask-making to explore identity formation in graduate students (art and engineering), faculty (art, medicine, engineering) and undergraduate students recently separated from military service (see, http://www.nationalgeographic.com/ healing-soldiers/).

\section{PROGRAM DESCRIPTION}

Developed in collaboration with a certified art therapist, our process is a co-curricular, non-graded mask-making

Published online March 19, 2019
PIF curriculum as a form of "reflective expression." Using dedicated prompts (Table 1), each student uses a blank papier-mâché mask to create a representation of their sense of self in the broader context of medical education. After students have completed work on their mask, they are invited to a group processing activity where they can voluntarily share the meaning behind their masks with their peers. Respecting that not all students may be comfortable sharing the stories of their masks, they are also asked to write a reflective essay to describe their masks (Fig. 1). We have found that key transitional time periods to explore PIF include entry to medical school ("Who Am I?"), transition to clinical clerkships ("Who Have I Become?"), and just prior to graduation ("Who Do I Want To Be?").

Table 1 Sample Prompts for Mask-Making and Accompanying Narrative

\begin{tabular}{|c|c|}
\hline Sample prompts & Learner stage \\
\hline $\begin{array}{l}\text { 1. What aspects of your identity do you } \\
\text { like to present to others? } \\
\text { a. Biographical information: (where are } \\
\text { you from, where did you go to school, } \\
\text { what did you study, ...) } \\
\text { b. Experiences and accomplishments: } \\
\text { c. Hopes and fears: } \\
\text { d. Likes and dislikes: } \\
\text { 2. What labels or adjectives would you } \\
\text { like others to use when they describe } \\
\text { you? } \\
3 \text {. What are some aspects of your } \\
\text { identity that you may not present to } \\
\text { others but that you still want them to } \\
\text { know about? (These are ideas you might } \\
\text { want to include on the inside of your } \\
\text { mask.) }\end{array}$ & $\begin{array}{l}\text { Beginning of medical } \\
\text { school ("Who Am I") }\end{array}$ \\
\hline $\begin{array}{l}\text { 1. We'd like to ask you to think about } \\
\text { your experiences to date in medical } \\
\text { school. Who were you when you } \\
\text { started? Who are you now? Are there } \\
\text { specific events, or a history of events, } \\
\text { during your medical education that } \\
\text { stand out in your mind? }\end{array}$ & $\begin{array}{l}\text { Transition to Clerkship } \\
\text { ("Who Have I Become") }\end{array}$ \\
\hline $\begin{array}{l}\text { 1. We would like to give you an } \\
\text { opportunity to candidly express } \\
\text { yourself. What would you like to tell us } \\
\text { about yourself or about your } \\
\text { experiences in medical school? What } \\
\text { elements of self have stayed the same? } \\
\text { What has changed? What is your } \\
\text { representation of self as you transition to } \\
\text { residency? }\end{array}$ & $\begin{array}{l}\text { Transition to residency } \\
\text { ("Who Do I Want To Be?") }\end{array}$ \\
\hline
\end{tabular}




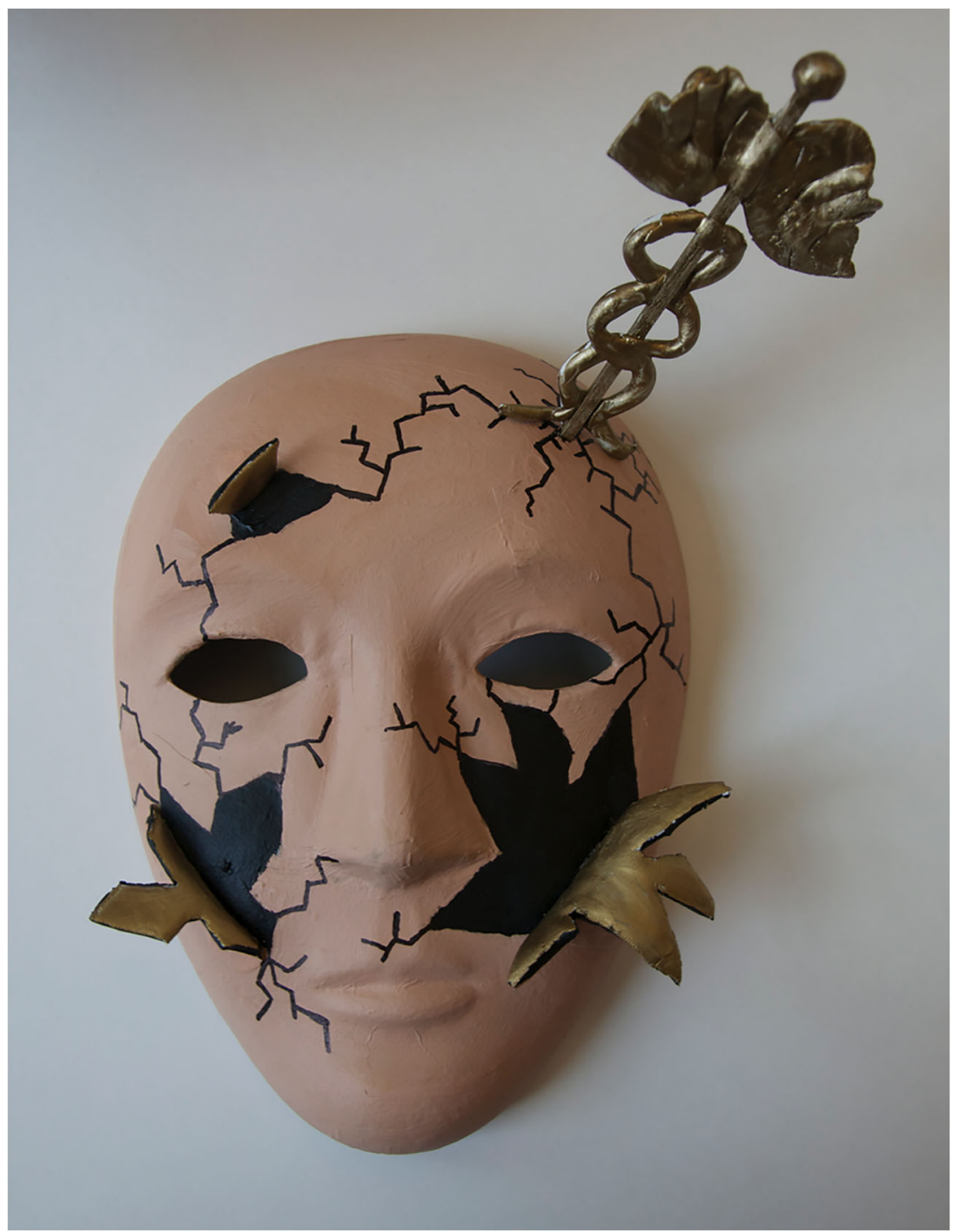

Fig. 1 Sample mask and narrative. "Starting with the mask as a whole: its featureless face represents when I feel like a nameless, faceless, medical student "object". I have spent the last year as a transient member of medical care teams in various specialties, hospitals, and states within the continental US, and the degree to which I am seen as a person sometimes feels entirely out of my control. The caduceus symbolizes medical school, and I suppose medicine in general, as I make my daily attempts of drinking from the fire hose that is medical knowledge in order to treat patients, impress real doctors, and avoid the wide range of catastrophic accidents of which it seems medical students are quite adept at finding. My mask demonstrates the process this seemingly constant strain has on me. First my armor cracks, the cracks spread, and suddenly I find that pieces of the person I once was are breaking away and exposing a darker, more jaded version of myself. The gold on the pieces breaking away from my mask are the good things I sometimes feel I am losing-love, friendship, compassion, empathy, trust. The black underneath represents the remaining worst parts of me-jealousy, callousness, fear. I should specify that this mask represents the worst of the worst. It's physical representation of the moments when I feel the most burnt out and beaten by the most strenuous parts of medical school." Used with permission

\section{PROGRAM EVALUATION}

To date, several hundred students have participated in the mask-making PIF activity. Using visual rhetoric and a listening guide to analyze the visual components of each mask and the accompanying written narratives, we have identified themes of role strain, isolation, burnout, and identity dissonance to be the most common in medical student masks. ${ }^{5}$ Although potentially limited by scope and generalizability, our findings suggest that the students are able to reflect deeply on personal and professional identity-related issues and express these through the mask-making experience. This learnercentric approach embraces art as both product and process and appears to facilitate each student's individual ability to reflect upon and learn about themselves.

\section{DISCUSSION}

Mask-making can be used to examine PIF as a process of reflective expression. We have found mask-making to be a safe and engaging way for students to explore their developing sense of self within the community of medical practice. Students have responded positively to the process. They describe mask-making as provocative, liberating, and fun. From an ontological perspective, the most persuasive illustrations of the power of mask- 
making to support student reflection and identity formation are the masks and accompanying narratives (Fig. 1).

Recognizing that individuals view their present selves differently from their past or future selves, we feel that maskmaking represents a unique way to longitudinally examine identity formation. PIF occurs at a pace that is specific to each student's experiences and personal contextual factors. Maskmaking adds to the process of PIF as a unique form of reflective expression using elements of artistry and nonlinguistic expression. The expressive opportunities afforded by mask-making may provide additional insights into identity that are hard to capture in words, lending new direction to the scholarship of professional identity formation.

Acknowledgements: The authors gratefully acknowledge the contributions of all participating student-artists.

Corresponding Author: Mark B. Stephens, MD MS; Penn State University College of Medicine, University Park, Hershey, PA, USA (e-mail: mstephens3@pennstatehealth.psu.edu).

Funding Information The work was funded internally by the Uniformed Services University and the National Intrepid Center of Excellence.

\section{Compliance with Ethical Standards:}

Conflict of Interest: The authors declare that they do not have a conflict of interest.

Disclaimer: The views expressed in this manuscript are solely those of the authors and do not necessarily reflect those of the Uniformed Services University of the Health Sciences or the US Department of Defense.

\section{REFERENCES}

1. Cruess RL, Cruess SR, Boudreau JD, et al. Reframing medical education to support professional identity formation. Acad Med 2014; 89:1446-1451.

2. Dyrbye LN, West CP, Satele, D et al. Burnout among US medical students, residents and early career physicians relative to the general US population. Acad Med 2014; 89(3): 443-451.

3. Rotenstein LS, Ramos MA, Torre M, et al. Prevalence of depression, depressive symptoms and suicidal ideation among medical students: A systematic review and meta-analysis. JAMA 2016; 316(21): 2214-2236.

4. Ballengee-Morris C, Taylor PG. You can hide but you can't run: Interdisciplinary and culturally sensitive approaches to mask making. Art Education 2005; 58: 12-17.

5. Joseph $\mathbf{K}$, Bader, $\mathbf{K}$, Wilson, $\mathbf{S}$, et al. Unmasking identity dissonance: Exploring medical students' professional identity formation through mask making. Perspect Med Ed 2017; 6(2): 99-107.

Publisher's Note Springer Nature remains neutral with regard to jurisdictional claims in published maps and institutional affiliations. 